\title{
Troglitazone inhibits cell proliferation by attenuation of epidermal growth factor receptor signaling independent of peroxisome proliferator-activated receptor $\gamma$
}

\author{
Xiaoqi $\mathrm{Li}^{1}$, Xuanming Yang ${ }^{1}$, Youli Xu${ }^{1}$, Xuejun Jiang ${ }^{2}$, Xin $\mathrm{Li}^{3}$, Fajun Nan ${ }^{3}$, Hong Tang ${ }^{1}$ \\ ${ }^{I}$ Center for Infection and Immunity and National Laboratory of Biomacromolecules, Institute of Biophysics, Chinese Academy of \\ Sciences, Beijing 100101, China; ${ }^{2}$ Institute of Microbiology, Chinese Academy of Sciences, Beijing 100080, China; ${ }^{3}$ Shanghai In- \\ stitute of Materia Medica, Chinese Academy of Sciences, Shanghai 201203, China
}

Peroxisome proliferator-activated receptors (PPAR) belong to the nuclear hormone receptor superfamily of ligand-dependent transcription factors. Recent results have shown that agonists of PPAR $\gamma$, such as troglitazone (TGZ), can inhibit cell proliferation and promote cell differentiation independent of PPAR $\gamma$. In the present study, we provide evidence that TGZ may bind directly to EGFR and trigger its signaling and internalization independent of PPAR $\gamma$. Detailed studies revealed that prolonged incubation with TGZ effectively attenuated EGFR signaling by targeting the receptor to the endo-lysosomal degradation machinery. Although the extracellular signal-regulated kinasesignaling pathway was transiently activated by TGZ in EGFR overexpressing cancer cells, inhibition of EGF-induced Akt phosphorylation most likely accounted for the growth arrest of tumor cells caused by TGZ at pharmacologically achievable concentrations. Therefore, we have provided a new line of evidence indicating that TGZ inhibits cell proliferation by promoting EGFR degradation and attenuating Akt phosphorylation.

Keywords: EGFR, PPAR $\gamma$, troglitazone, endocytosis, growth arrest

Cell Research (2009) 19:720-732. doi: 10.1038/cr.2009.53; published online 5 May 2009

\section{Introduction}

Peroxisome proliferator-activated receptors (PPARs) belong to the nuclear hormone receptor superfamily that functions as ligand-activated transcription factors [1]. Upon ligand stimulation, PPARs heterodimerize with a retinoid $\mathrm{X}$ receptor and bind to the specific peroxisome proliferator response element (PPRE), modulating transcription rates of target genes, most of which are involved in lipid metabolism [2]. Of the three types of receptors (PPAR $\alpha, \beta / \delta$ and $\gamma$ ) identified thus far [3-5], PPAR $\gamma$ has been well characterized and is known to be a master lipid sensor and regulator of adipogenesis $[2,6]$.

The function and clinical application of PPAR $\gamma$ ligands, including synthetic thiazolidinediones (TZD), and

Correspondence: Hong Tang

Tel: +86-10-64888438; Fax: +86-10-64830432

E-mail: tanghong@moon.ibp.ac.cn

Received 25 September 2008; revised 29 October 2008; accepted 13

November 2008; published online 5 May 2009
non-TZD agonists, such as the natural prostaglandin 15deoxy- $\Delta^{12,14}$-prostaglandin J2 (15d-PG-J2) and certain long-chain fatty acid and eicosanoid derivatives, have been studied extensively [6]. The finding that PPAR $\gamma$ ligands can inhibit cell proliferation and promote adipocyte differentiation [7] has recently attracted much interest because of their potential use as anti-cancer therapeutics. For example, pioglitazone blocks the cell cycle and causes differentiation of primary liposarcoma cells in vitro and troglitazone (TGZ) retards tumor growth in patients $[8,9]$. TGZ has been shown to inhibit proliferation of a variety of human cancer cells including colorectal cancer, breast cancer, glioblastoma, leukemia and prostate cancer xenografts [10-13]. Detailed analysis has indicated that TGZ elicits PPAR $\gamma$-independent proapoptotic effects. Firstly, TGZ can induce MCF7 breast cancer cells to undergo apoptosis that is dependent on upregulation of GADD45 expression [14]. Proapoptotic activity of TGZ has also been shown to be dependent on the expression of tumor suppressor EGR-1 in HCT116 colorectal cancer cells [15] and downregulation of 
STAT3 phosphorylation via activated protein tyrosine phosphatase 1B in human glioma cells [16]. Secondly, TGZ inhibits cell growth possibly by targeting mitochondrial respiratory functions directly [17] or by inhibiting the pro-survival function of $\mathrm{Bcl}-2 / \mathrm{Bcl}-\mathrm{XL}$ in $\mathrm{LNCaP}$ prostate cancer cells that are deficient in PPAR $\gamma$ [18]. Finally, PPAR $\gamma$ gene-targeting experiments have shown that TGZ and ciglitazone (Cig) efficiently inhibit tumor growth of both PPAR $\gamma^{+/+}$and PPAR $\gamma^{-/-}$mouse embryonic stem cells [19].

ERBB protein kinases are a subclass of the receptor tyrosine kinase superfamily consisting of four members: the epidermal growth factor receptor (EGFR)/ERBB1, neu/ERBB2, ERBB3 and ERBB4 [20]. Binding of EGF initiates receptor homo- and hetero-dimerization, and activates intrinsic tyrosine kinase that in turn autophosphorylates specific tyrosine residues in the cytoplasmic domain of EGFR. These phospho-tyrosines serve as docking sites to recruit Src homology 2 (SH2) and phosphotyrosine-binding (PTB) domain proteins, pivotal steps in signal transduction [20, 21]. For example, binding of adaptor proteins Src homology collagen (Shc) and growth factor-receptor-bound protein 2 (Grb2) to phosphorylated EGFR (at positions Y1148/Y1173, and Y1068/Y1086, respectively) is essential for the activation of both Ras GTPase and extracellular signal-regulated kinase (Erk1/2)-signaling pathways. On the other hand, it is generally accepted that ligand binding to EGFR leads to rapid endocytosis of ligand-receptor complexes via clathrin-coated pits, and a significant fraction of internalized receptor is sorted from early endosomes to multivesicular bodies and eventually targeted to lysosomes for degradation, downregulating both EGFR protein levels and receptor signaling $[22,23]$. More importantly, EGFR and ERBB2 are overexpressed, aberrantly activated or mutated in a wide variety of tumors and are tightly associated with tumor aetiology and progression [20, 24]. Drugs and antibodies directed against EGFR and ERBB2 have provided very promising target-specific therapies against cancer [20].

In the present study, we provide evidence that the TGZ-activated EGFR-Erk1/2-signaling pathway is independent of PPAR $\gamma$, but dependent on Grb2. Our detailed analyses revealed for the first time that TGZ attenuates EGFR signaling specifically by effectively targeting the receptor to the endo-lysosomal degradation machinery. Although the Erk1/2-signaling pathway was transiently activated by TGZ, downregulation of basal and EGFinduced Akt activation may account for the growth arrest of tumor cells in response to TGZ treatment. Therefore, this novel mechanism of attenuation of EGFR signaling by TGZ may shed light on the anti-neoplastic effects of this PPAR $\gamma$ ligand.

\section{Results}

Troglitazone activated EGFR signaling independent of PPAR $\gamma$

A few studies have suggested that PPAR $\gamma$ ligands might cross-activate the EGFR-Erk1/2 pathway [25, 26]. However, molecular mechanisms for this activation are still being explored. To assess how TGZ activates EGFR signaling, we stably expressed human EGFR in porcine aorta endothelial (PAE) cells (designated as PAE-EGFR). We chose to use PAE cells because they are deficient in endogenous EGFR. TGZ $(25-50 \mu \mathrm{M}, 24 \mathrm{~h}$ incubation) activated PPAR $\gamma$ with a typical 2-3-fold increase in PPRE luciferase reporter activity (Figure 1A), in good agreement with previous reports [27], while EGF failed to cross-activate the PPRE reporter. TGZ stimulation resulted in rapid Erk1/2 phosphorylation in PAE-EGFR cells, but not in PAE cells (Figure 1B), suggesting that TGZ could elicit signaling through EGFR. In contrast to other reported results [28], Erk1/2 phosphorylation decayed with prolonged incubation of TGZ in PAE-EGFR cells, especially at the higher dose of $50 \mu \mathrm{M}$ (Figure 1C), suggesting transient Erk1/2 activation by TGZ in cells overexpressing EGFR.

It is still unclear whether or not activation of the EGFR-Erk1/2-signaling pathway by TZDs involves PPAR $\gamma$. To address this issue, we first measured the capacity of various TZDs to transiently activate Erk1/2 phosphorylation in PAE-EGFR cells. Earlier studies established the ranking order of PPAR $\gamma$-TZD binding affinity to be Rosi $>$ Pio $>$ TGZ > Cig [29]. However, in this study TZDs with relatively lower PPAR $\gamma$ affinities activated the Erk1/2-signaling pathway more efficiently than those with higher affinities (TGZ $>$ Cig $>>$ Rosi/ Pio, Figure 1D), even though all these agonists activated PPAR $\gamma$ to a similar extent in PPRE reporter assays (data not shown). Indeed, Rosi and Pio did not induce Erk1/2 phosphorylation at all. Secondly, pretreatment of PAEEGFR cells with GW9662, an irreversible inhibitor of PPAR $\gamma$, reduced TGZ activation of PPRE reporter activities as expected, but did not interfere with Erk1/2 phosphorylation induced by TGZ (Figure 1E, left panel). Thirdly, transient transfection of PAE-EGFR cells with the dominant negative mutant of PPAR $\gamma(\operatorname{PPAR} \gamma-\mathrm{DN})$ reduced TGZ-induced PPRE activities (Figure 1E, right panel). Under the same conditions, however, neither wild type nor PPAR $\gamma$-DN affected TGZ-induced Erk1/2 phosphorylation (Figure 1E, right panel). Finally, TGZ induced Erk1/2 phosphorylation in LNCaP cells, which are deficient in PPAR $\gamma$ (Supplementary information, Fig- 
A

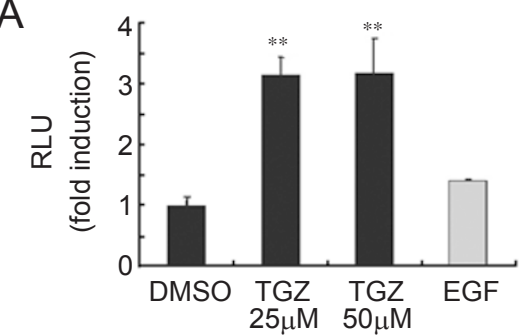

C

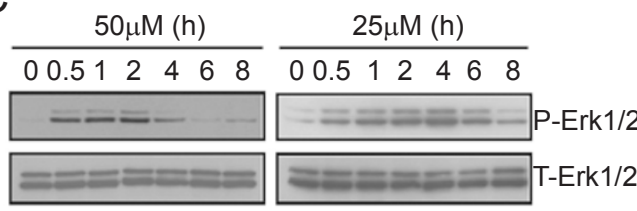

D

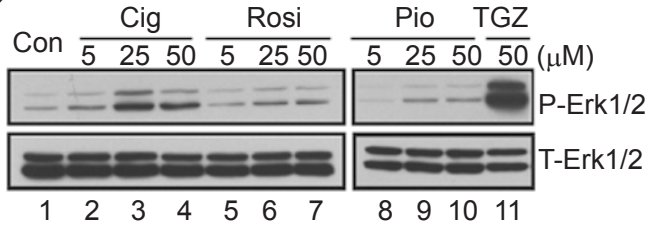

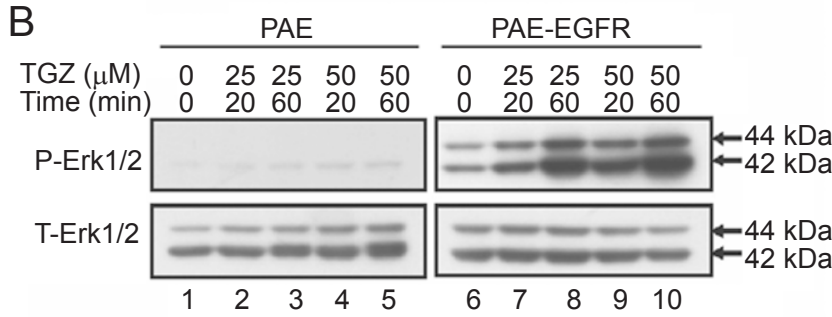

$E$
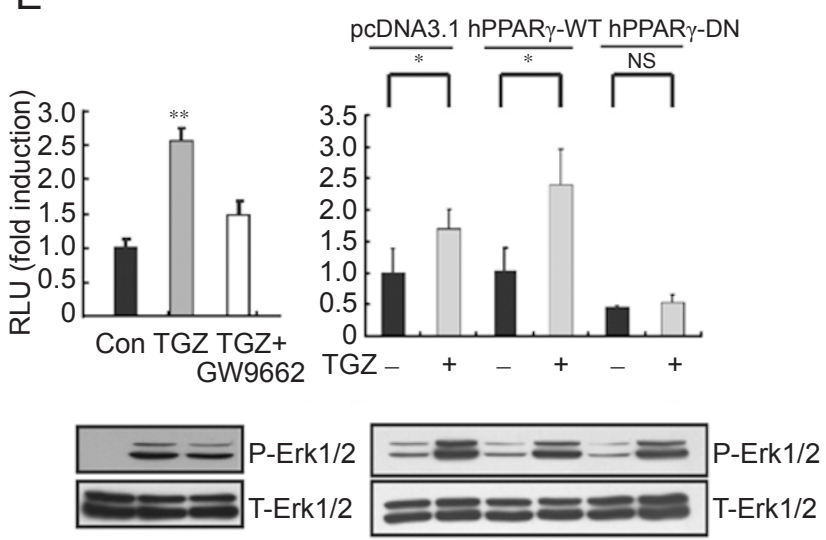

Figure 1 Activation of EGFR signaling by TGZ is PPAR $\gamma$-independent. (A) TGZ activates PPAR $\gamma$ in PAE-EGFR cells. PAEEGFR cells $(50 \%$ confluence) were transiently co-transfected with PPRE3-tk-luc reporter $(0.2 \mu \mathrm{g})$ and phRL-CMV reference plasmid ( $3 \mathrm{ng})$ in triplicate. TGZ $(25 \mu \mathrm{M}$ or $50 \mu \mathrm{M})$ or $100 \mathrm{ng} / \mathrm{ml}$ EGF was added $24 \mathrm{~h}$ later and incubated for an additional $24 \mathrm{~h}$. Cells were lysed and dual luciferase assays were performed. Data are the average of three independent experiments (means $\pm S D$ ) and are presented as the ratios of Firefly luciferase activity/Renilla luciferase activity after normalizing to DMSO (vehicle) **P $P<0.01$, compared with the control. (B) TGZ activation of Erk1/2 is dependent upon EGFR. PAE (lanes 1-5) and PAE-EGFR (lanes 6-10) cells were grown to near confluence and serum-starved in F12 medium for 30 min before being stimulated with 25 or $50 \mu \mathrm{M}$ TGZ for the times indicated. Phosphorylation of Erk1/2 was assessed by western blotting with antibodies specific to phospho-Erk1/2 (P-Erk1/2) and to total Erk1/2 (T-Erk1/2) as a loading control. (C) Erk1/2 phosphorylation by TGZ is transient. PAE-EGFR cells were treated with 25 or $50 \mu \mathrm{M} \mathrm{TGZ}$ for $0.5,1,2,4,6$ or $8 \mathrm{~h}$ and Erk $1 / 2$ activation was assessed as in (B). (D) TZDs activate Erk1/2 differently. PAE-EGFR cells were grown to near confluence and serum-starved in F12 medium for 30 min before being mock stimulated (lane 1) or treated with 5,25 or $50 \mu \mathrm{M} \mathrm{Cig}$ (lanes 2-4), Rosi (lanes 5-7) or Pio (lanes 8-10) for $30 \mathrm{~min}$. TGZ (50 $\mu \mathrm{M}$, lane 11) was applied similarly as a positive control. Phosphorylation of Erk1/2 was assessed as in (B). (E) Erk1/2 phosphorylation by TGZ is PPAR $\gamma$-independent. Left panel: GW9662 could not block TGZ-induced Erk1/2 activation. PAE-EGFR cells were seeded in 24-well plates and PPRE3 reporter assays were performed as in (A), except that the transfectants were pre-treated with (blank bar) or without (gray bar) $2.5 \mu \mathrm{M} \mathrm{GW9662}$ for $1 \mathrm{~h}$ before addition of TGZ. Phosphorylation levels of Erk1/2 were assessed as in (B). Right panel: The dominant negative mutant of hPPAR $\gamma$ did not inhibit Erk1/2 activation by TGZ. PAE-EGFR cells were transiently co-transfected with pcDNA3.1, pcDNA3.1-hPPAR $\gamma$-WT or pcDNA3.1-hPPAR $\gamma$-DN in combination with a PPRE3 reporter plasmid (phRL-CMV as reference). After 1 day, transfectants were mock-treated (black bars) or treated with $50 \mu \mathrm{M}$ TGZ (gray bars) for $12 \mathrm{~h}$ before dual luciferase assays were performed as in (A). $* P<0.05 ; * P<0.01$, compared with the control. NS, no statistical significance. In parallel, phosphorylation levels of Erk $1 / 2$ were analyzed as in (B).

ure S1A). Taken together with the fact that the minimum concentration of TGZ required to elicit Erk1/2 phosphorylation ( $\geq 5 \mu \mathrm{M}$, data not shown) was much higher than its $\mathrm{EC}_{50}$ for PPAR $\gamma$-signaling activation [29], the aforementioned evidence strongly indicates that TGZ-activated Erk1/2 phosphorylation is independent of PPAR $\gamma$ in PAE-EGFR cells.
Troglitazone activation of EGFR signaling is dependent on Grb2

Earlier studies suggested that transient TGZ-activated Erk1/2 phosphorylation was sensitive to EGFR kinase inhibition [25], but it is unclear whether the proximal adaptor proteins Grb2 and/or Shc are required to transduce TGZ signaling. To address this question, we generated 
a series of EGFR mutant derivatives by either deletion of the cytoplasmic domain leaving the kinase domain intact (C'1022) or by phenylalanine substitution of Grb2 (Y1068/1086F) or Shc (Y1148/1173F) binding sites (Figure 2A, top panel). Stable expression of these EGFR mutants was similar (Figure 2B) and apparently did not interfere with PPRE activation by TGZ (data not shown). However, robust Erk1/2 phosphorylation in PAE-EGFR cells was severely reduced in PAE-EGFR-C'1022 cells (Figure 2B). Furthermore, in contrast to PAE-EGFRY1148/1173F cells, PAE-EGFR-Y1068/1086F cells showed a specific decrease in Erk1/2 phosphorylation in response to TGZ (Figure 2B), suggesting that while binding of Shc to pY1148/1173 in EGFR is not critical, Grb2 binding to pY1068/1086 may be critical for transient Erk1/2 activation by TGZ. Intriguingly, the dependence on Grb2 for TGZ induction of Erk1/2 phosphorylation mimicked that by EGF at lower concentrations (1-2 ng/ $\mathrm{ml})$ in PAE-EGFR cells. EGF at higher concentrations (20 $\mathrm{ng} / \mathrm{ml}$ ) bypassed the requirement for Grb2 binding and even for the entire C-terminal domain of EGFR (Figure 2C), supporting the notion that a clathrin-independent pathway was evoked $[30,31]$. These findings indicate that TGZ could activate EGFR-Erk1/2 in a similar manner to EGF, and that the activation of the EGFR-Erk1/2signaling pathway by TGZ requires Grb2.

Non-genomic ligand TGZ may bind directly to EGFR and induce its endosomal compartmentalization

To circumvent technical difficulties in direct measurements of the binding affinity of EGFR for TGZ, we first performed competition binding assays to assess whether TGZ interferes with EGF in cognate receptor binding. Results indicated that pre-incubation of PAE-EGFR cells

A
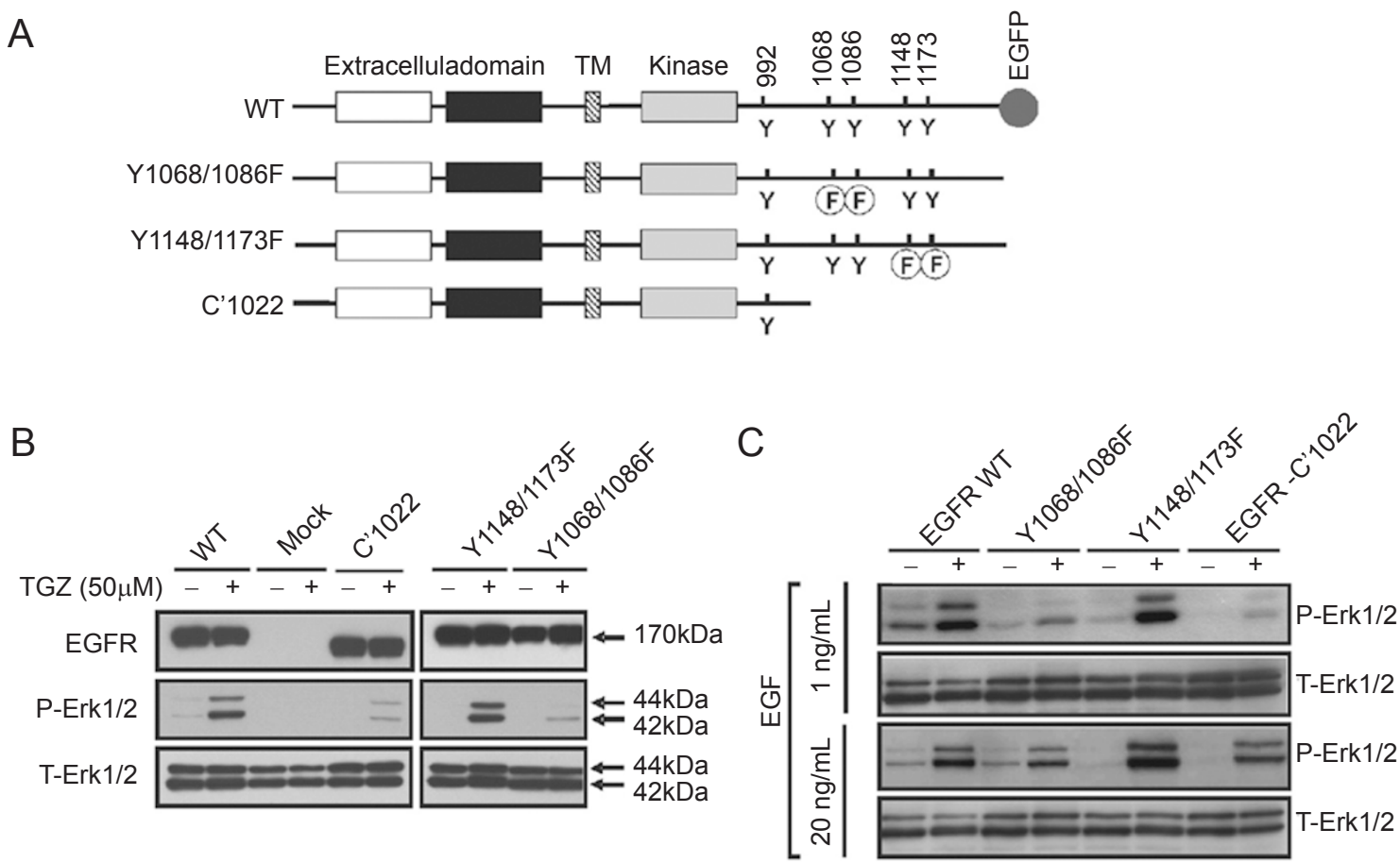

Figure 2 EGFR-Erk1/2 activation by TGZ is Grb2-dependent. (A) A schematic diagram of wild-type EGFR (WT) is shown with the extracellular (empty and black boxes), transmembrane (TM, dashed boxes), intracellular kinase (gray boxes) and C-terminal domain with each tyrosine $(Y)$ position indicated. Mutant EGFR with the C-terminal 164 amino acids truncated (EGFR-C'1022), phenylalanine (F) substitution of Grb2 (EGFR-Y1068/1086F) or Shc (EGFR-Y1148/1173F) binding sites are indicated. Where indicated, GFP (gray dot) fused to EGFR was also used. (B) TGZ-induced Erk1/2 activation is dependent on Grb2. PAE, PAE cells stably expressing EGFR or mutant derivatives were selected and expression levels of different exogenous EGFRs were verified by immunoblotting with anti-EGFR antibodies. These cells were stimulated with $50 \mu \mathrm{M}$ TGZ for 30 min and phosphorylation of Erk1/2 was assessed as in Figure 1B. (C) Erk1/2 activation by TGZ mimics that by low concentrations of EGF. PAE-EGFR and PAE cells expressing various mutant EGFRs were grown to near confluence and serumstarved in F12 medium for 30 min before being stimulated with low $(1 \mathrm{ng} / \mathrm{ml})$ or high concentration $(20 \mathrm{ng} / \mathrm{ml})$ of EGF for 10 min. Phosphorylation of Erk1/2 was analyzed by Western blotting in a similar manner. Data presented are representative of three independent experiments. 


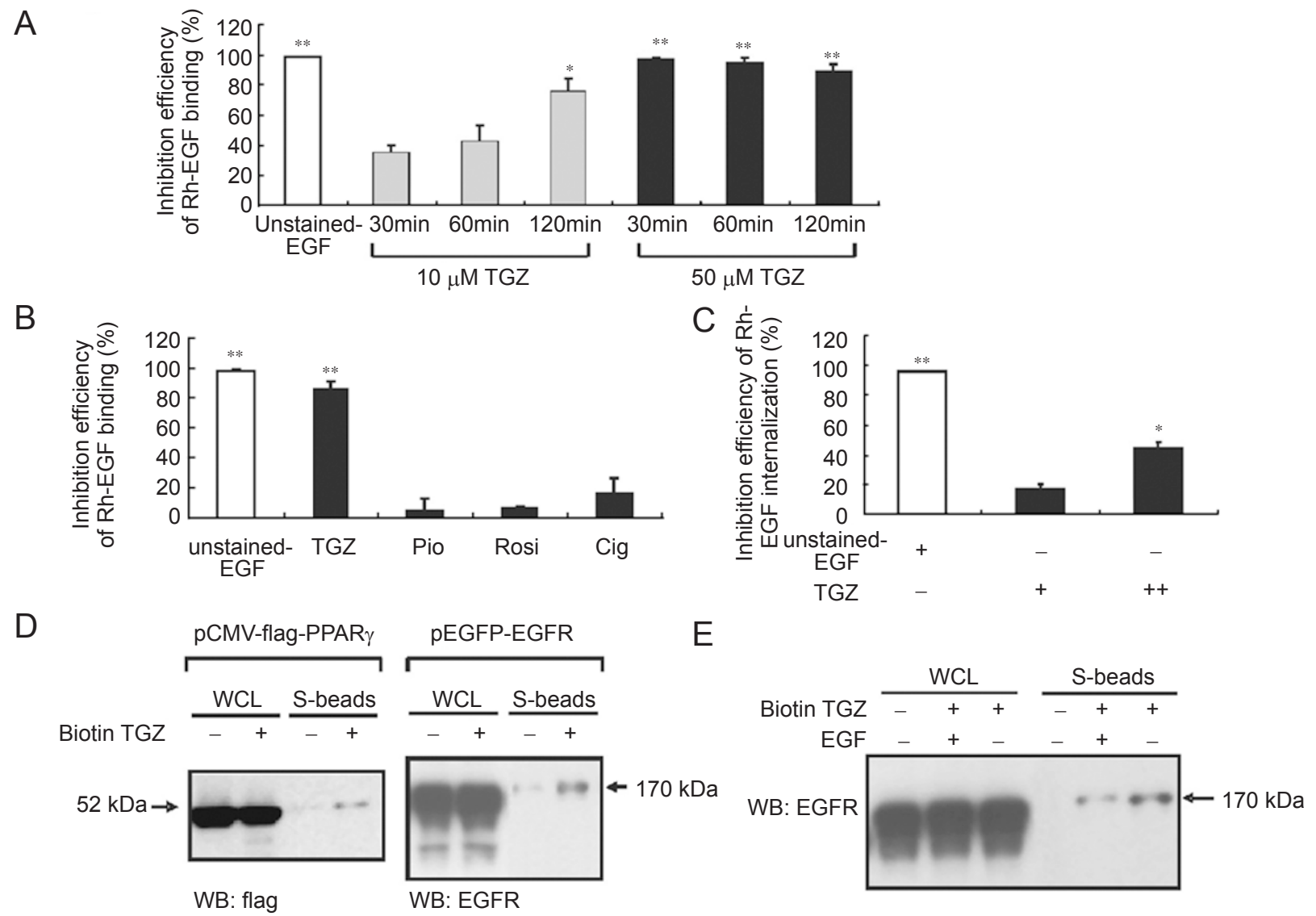

Figure 3 TGZ functions via direct targeting of EGFR. (A) TGZ inhibits EGF binding to EGFR. PAE-EGFR cells were serumstarved overnight and then chilled on ice for $20 \mathrm{~min}$. After treating cells with TGZ (10 or $50 \mu \mathrm{M})$ at $4^{\circ} \mathrm{C}$ for the times indicated, Rh-EGF (2 ng/ml) was added to cells at $4^{\circ} \mathrm{C}$ for a further 1 hour. Recombinant non-conjugated EGF (100 ng/ml) was used instead of TGZ as a positive control. Cells were collected and the mean fluorescence intensity of Rh-EGF bound to the cell surface was measured by flow cytometry. Data were averaged (means $\pm \mathrm{SE}$ ) from three experiments. $* P<0.05$; $* * P<0.01$, compared with Rh-EGF treated alone. (B) Other TZDs do not interfere with the EGF/EGFR interaction. Binding efficiency for Rh-EGF to PAE-EGFR cells was assessed as in (A), except that $50 \mu \mathrm{M}$ pioglitazone, rosiglitazone or ciglitazone was used. Data (means \pm SE) were the average of three independent experiments. $* * P<0.01$, compared with Rh-EGF treated alone. (C) TGZ inhibits EGFR internalization in a dose-dependent manner. PAE-EGFR cells were pre-incubated with 10 or $50 \mu \mathrm{M}$ TGZ for $30 \mathrm{~min}$ followed by $2 \mathrm{ng} / \mathrm{ml}$ Rh-EGF at $37^{\circ} \mathrm{C}$ for $6 \mathrm{~min}$. Surface Rh-EGF was washed off with acid buffer and receptor internalization efficiency was measured directly for rhodamine intracellular fluorescence intensity by flow cytometry. $* P<0.05$; $* * P<0.01$, compared with Rh-EGF treated alone. (D) TGZ can directly pull down EGFR. 293T cells overexpressing pCMVflag-PPAR $\gamma$ or EGFR were stimulated with biotin-TGZ $50 \mu \mathrm{M}$ for $1 \mathrm{~h}$ at $37^{\circ} \mathrm{C}$. Cell lysates were then incubated with Streptavidin-Sepharose beads at room temperature for $1 \mathrm{~h}$. The bound proteins were resolved using SDS-PAGE and immunoblotted with anti-flag or anti-EGFR antibodies. 'S-beads', Streptavidin beads. (E) TGZ can directly pull down EGFRs in PAE-EGFR cells. After incubation with or without EGF for $10 \mathrm{~min}$, PAE-EGFR cells were mock-treated or stimulated with biotin-TGZ $50 \mu \mathrm{M}$ for $1 \mathrm{~h}$ at $37^{\circ} \mathrm{C}$. Cell lysates were then incubated with Streptavidin-Sepharose beads at room temperature for $1 \mathrm{~h}$. The bound proteins were resolved using SDS-PAGE and immunoblotted with anti-EGFR antibodies.

with TGZ caused a dose- and time-dependent inhibition of Rhodamine-labeled EGF (Rh-EGF) binding to cells at $4{ }^{\circ} \mathrm{C}$ (Figure 3A). Cig slightly inhibited Rh-EGF/EGFR binding, whereas other TZDs failed to do so (Figure 3B), suggesting a rather specific interaction between TGZ and EGFR. Unstained EGF (as a positive control) abolished the binding of Rh-EGF to EGFR. When the same reac- tions were conducted at $37^{\circ} \mathrm{C}$, increasing concentrations of TGZ exhibited a dose-dependent inhibition of Rh-EGF internalization (Figure 3C). Biotinylated TGZ (biotin-TGZ) was used to treat $293 \mathrm{~T}$ cells transiently overexpressing EGFR. After rinsing off excessive biotinTGZ from the cell surface, internalized EGFR in cell lysates was pulled down by streptavidin beads (Figure 3D). 
A
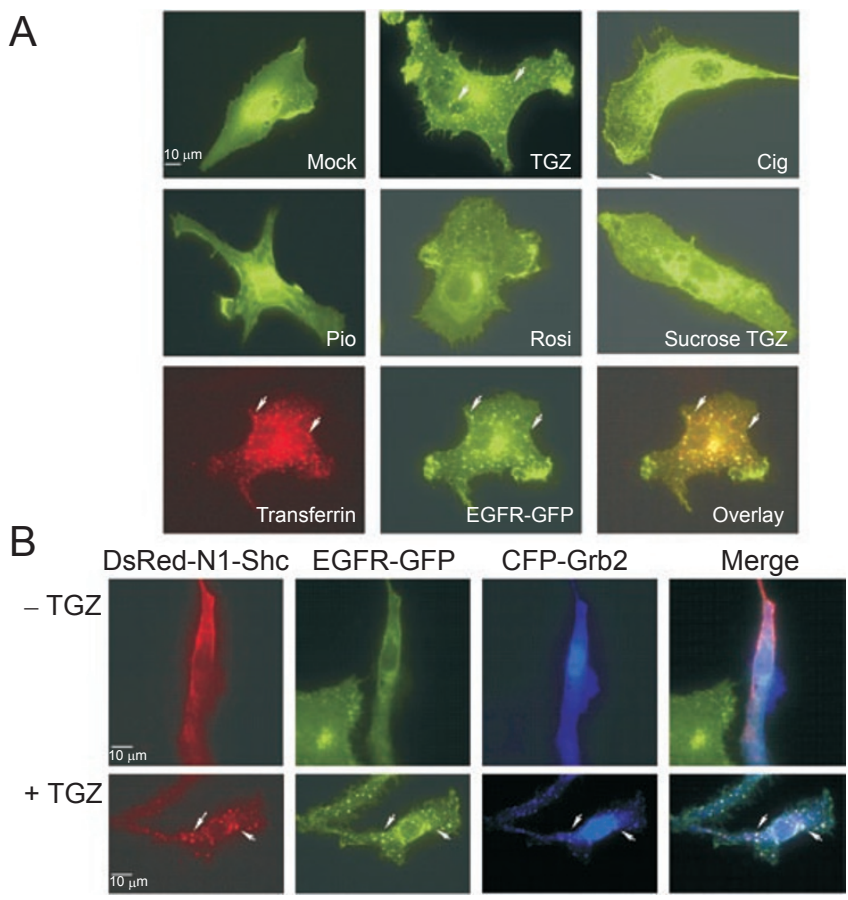

Figure 4 TGZ triggers endosomal compartmentalization of EGFR. (A) TGZ triggers endocytosis of EGFR. PAE-EGFRGFP cells were mock-treated with DMSO or different TZD compounds as indicated for $30 \mathrm{~min}$, and fluorescence images were acquired through the GFP filter channel. PAE-EGFR-GFP cells were pretreated with either $0.45 \mathrm{M}$ sucrose or Transferrin-Texas Red $(5 \mu \mathrm{M})$ before addition of TGZ. Images were acquired through the GFP and RFP filter channels, respectively. Arrows indicate intracellular vesicles of EGFR-GFP (green) and Transferrin receptors (red). (B) Shc and Grb2 colocalize with EGFR after TGZ stimulation. PAE-EGFR-GFP cells were transiently transfected with DsRed-N1-Shc or CFP-Grb2. 1 day after transfection, cells were stimulated with $50 \mu \mathrm{M}$ TGZ for 30 min. TGZinduced colocalization (arrows) of transiently transfected Grb2CFP and DsRed-Shc with EGFR-GFP in PAE-EGFR-GFP cells is depicted in the bottom panel by overlay of images acquired through RFP (red), CFP (blue) and GFP (green) filter channels, respectively. Scale bars, $10 \mu \mathrm{M}$.

Biotin-TGZ pulled down transiently overexpressed FlagPPAR $\gamma$ (used as a positive control) in 293T cells. Preincubation of PAE-EGFR cells with EGF also interfered with biotin-TGZ pulldown efficiency of EGFR (Figure $3 \mathrm{E})$. These results strongly suggest that TGZ can bind to EGFR directly to induce its downstream signaling.

To facilitate the measurement of EGFR internalization, we stably expressed EGFR-GFP in PAE cells (PAEEGFR-GFP). Fluorescence microscopy demonstrated that TGZ caused rapid EGFR internalization in 15-20 min and that engulfed receptors formed punctated vesicles typical of early endosomes (Figure 4A). Structural differences in TZD compounds seem to determine their specificity for inducing EGFR internalization, as TGZ was the only member of the TZDs that induced endocytosis of EGFR (Figure 4A). This correlated well with the ability of TZDs to bind to EGFR and activate EGFR signaling. Internalized EGFR colocalized with both transferrin receptors (Figure 4A, depicted by transferrinTexas Red) and transiently co-expressed Grb2-CFP and DsRed2-Shc (Figure 4B). Hypertonic preconditioning (0.45 M sucrose) of cells abolished TGZ-induced EGFR internalization (Figure 4A). These results therefore suggest that TGZ mimicks EGF in inducing EGFR endocytosis via the typical endo-lysosomal pathway. GW9662, on the other hand, did not prevent EGFR endocytosis or EGFR-GFP/Grb2/Shc colocalization in the above experiments (data not shown), further suggesting that TGZ triggered EGFR endocytosis independent of PPAR $\gamma$. Therefore, TGZ mimicks EGF, not only in EGFR activation, but also in efficient EGFR internalization.

\section{Troglitazone induced EGFR degradation and inhibited cancer cell proliferation}

EGFR overexpression and/or defective internalization are often associated with many epithelial and brain cancers as a result of abnormal activation of mitogenicsignaling pathways, including the Erk pathway, leading to cellular transformation [20]. TGZ's anti-neoplastic properties prompted us to test whether it inhibits cancer cell proliferation by promoting EGFR degradation. Indeed, TGZ treatment initiated effective EGFR degradation in a time-dependent manner in PAE-EGFR cells (Figure 5A). Partial proteolysis was observed for EGFRY1068/1086F, probably because Grb2 binding to EGFR is crucial for EGFR internalization and degradation [32]. Furthermore, clonogenic assays showed that PAE-EGFR cell proliferation was inhibited by TGZ at pharmacologically achievable concentrations (5 and $10 \mu \mathrm{M})$. Such inhibition was alleviated in PAE-EGFR-Y1068/1086F cells, again suggesting that Grb2 binding to EGFR may be associated with efficient growth arrest by TGZ (Figure 5B). Reduction in EGFR levels may have occurred at the post-translational level because real-time RT-PCR analysis showed that EGFR mRNA remained invariant before or after TGZ treatment (Figure 5C). To confirm our results, we chose several cancer cell lines to test whether TGZ also induced EGFR degradation and growth arrest in transformed tumor cells. Results indicated that TGZ induced efficient degradation of endogenous EGFR in lung epithelial carcinoma A549 cells and prostate epithelial carcinoma Du145 cells, but not in human epidermoid carcinoma A431 or cervical epithelial carcinoma HeLa cells (Figure 5D, top panel). This pattern of EGFR deg- 

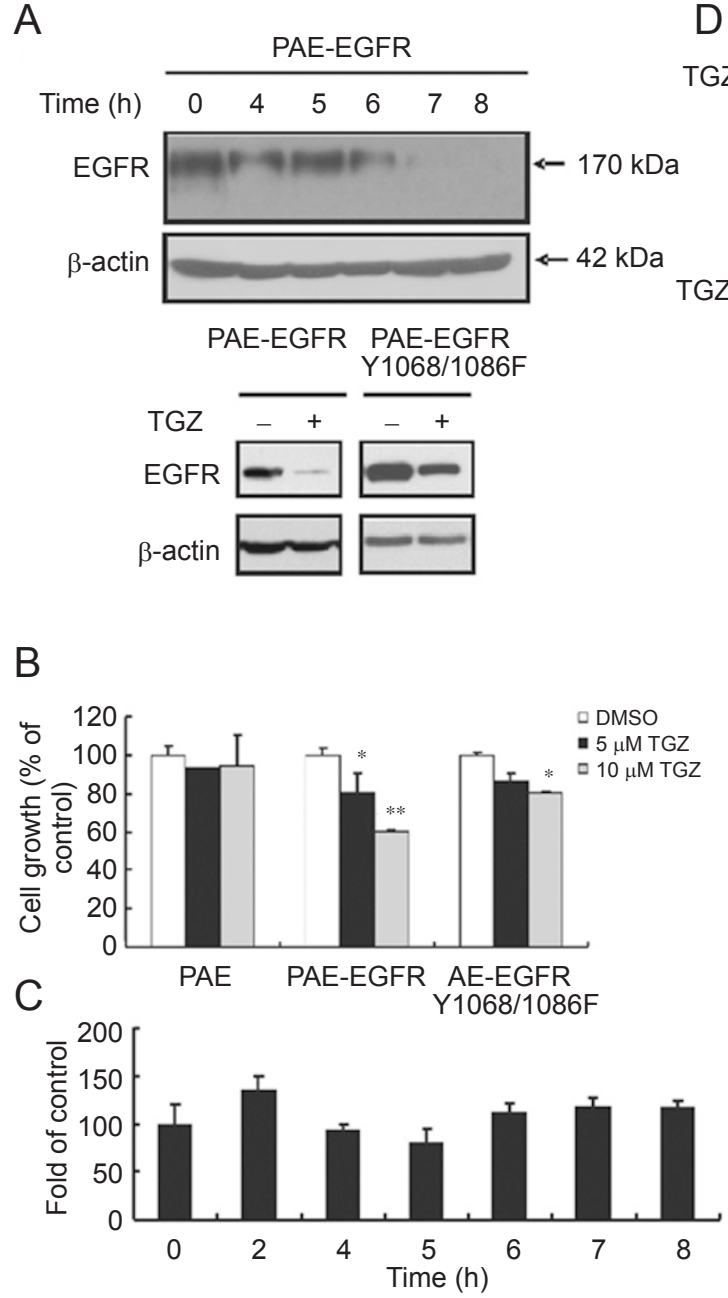

D TGZ (h) $\mathrm{A} 431$
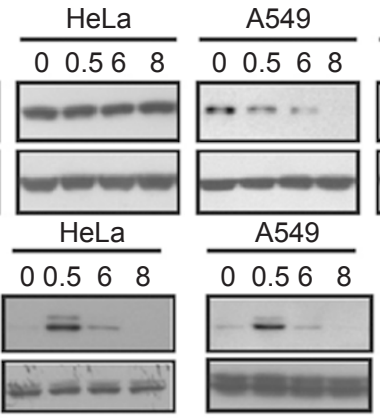
$\frac{D u 145}{0} 0.56 \quad 8$

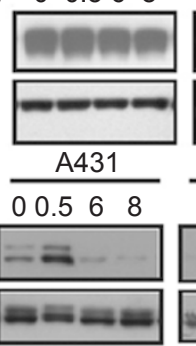
00.568

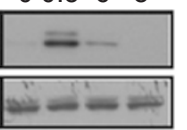

E

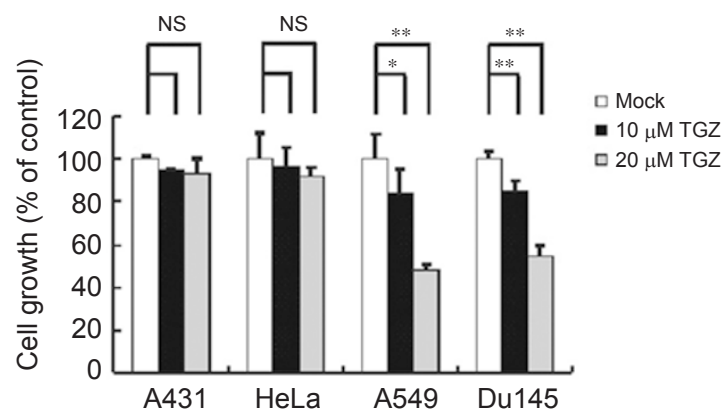

$\mathrm{F}$

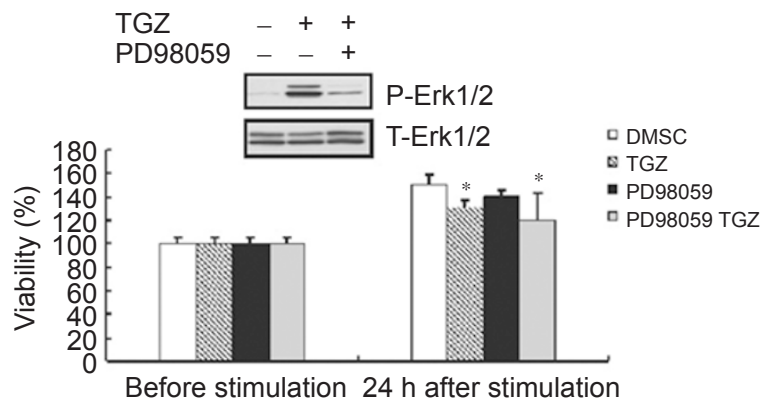

Figure 5 TGZ inhibits cell proliferation through EGFR degradation in PAE-EGFR cells and EGFR-overexpressing cancer cells. (A) Prolonged TGZ incubation leads to PAE-EGFR degradation. PAE-EGFR cells were incubated with $50 \mu M$ TGZ for the times indicated (top), or PAE-EGFR and PAE-EGFR-Y1068/1086F cells were stimulated with $50 \mu \mathrm{M} \mathrm{TGZ}$ for $8 \mathrm{~h}$ (bottom). EGFR was immunoblotted with anti-EGFR antibodies. $\beta$-actin was used as a loading control. (B) TGZ inhibits cell proliferation in clonogenic assays. PAE, PAE-EGFR or PAE-EGFR-Y1068/1086F cells were seeded on $60-\mathrm{mm}$ plates (300 cells/ plate) containing 5 or $10 \mu \mathrm{M} \mathrm{TGZ} .7$ days later, the colonies formed were counted and data averaged from four independent experiments (means $\pm \mathrm{SE}$ ). $* P<0.05$; ** $P<0.01$, compared with DMSO controls. (C) TGZ does not alter EGFR transcription. PAE-EGFR cells (80\% confluence) were stimulated with $50 \mu \mathrm{M} \mathrm{TGZ}$ for the times indicated. Real-time PCR analysis of EGFR mRNA expression was performed, and 18S RNA levels were used as internal controls. Data was collected from at least three separate experiments. (D) TGZ induced EGFR degradation in A549 and Du145 cells. A549, Du145, A431 or HeLa cells were incubated with TGZ $(10 \mu \mathrm{M})$ for the times indicated and EGFR levels were measured by immunoblotting. $\beta$-actin was used as a loading control. Phosphorylated Erk1/2 and total Erk1/2 were also tested. (E) TGZ inhibits tumor cell proliferation. Clonogenic assays were performed as in Figure 5B except that A549, Du145, A431 and HeLa cells were used and 10 or $20 \mu \mathrm{M}$ TGZ was applied. ${ }^{*} P<0.05 ; * * P<0.01$, compared with DMSO for each cell line. NS, no statistical significance. (F) TGZ inhibits cell proliferation independently of Erk $1 / 2$ activation. PAE-EGFR cells $\left(0.5 \times 10^{4} \mathrm{cells} /\right.$ well $)$ were pre-treated with or without $15 \mu \mathrm{M}$ PD98059 and then treated with $10 \mu \mathrm{M}$ TGZ for $24 \mathrm{~h}$. Cell proliferation was assessed by the WST-1 method. Data represent the average (means \pm SD) of three independent experiments. $* P<0.05$, compared with controls.

radation was consistent with TGZ-induced growth inhibition in clonogenic assays where TGZ inhibited growth of A549 and Du145 cells, but not of A431 or HeLa cells (Figure 5E).
Previous studies have shown that Erk1/2 activation is associated with an inhibitory effect of TGZ on tumor cell proliferation and progression [30, 33, 34]. However, in this study, pre-treatment of PAE-EGFR cells 
with PD98059, an inhibitor of Erk1/2, did not affect the growth inhibition by TGZ in cell proliferation assays (Figure 5F) or clonogenic assays (Supplementary information, Figure S2). TGZ-induced Erk1/2 phosphorylation was transient (Figure 1C) and such transient Erk1/2 activation was uniform in all tested tumor cells (Figure 5D, bottom panel), strongly suggesting that transient Erk1/2 activation may not be required for growth inhibi- tion by TGZ.

TGZ-mediated inhibition of Akt phosphorylation contributed to its inhibition of cancer cell proliferation

In addition to Ras-Erk1/2, there are at least two other major pathways downstream of ERBB receptors, namely PI3K-Akt and STAT3/5. Akt functions as a cardinal nodal point for transducing oncogenic signals from growth

A

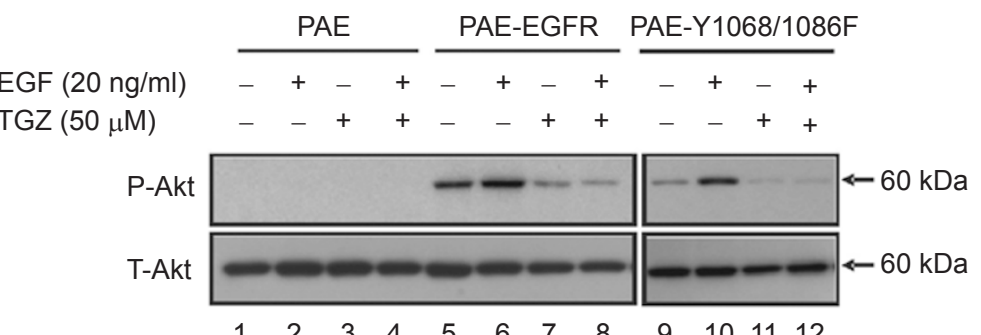

$\begin{array}{llllllllllll}1 & 2 & 3 & 4 & 5 & 6 & 7 & 8 & 9 & 10 & 11 & 12\end{array}$

CFP-myr-Akt $\frac{48 \mathrm{~h}}{+} \frac{5 \text { days }}{-+}$

B

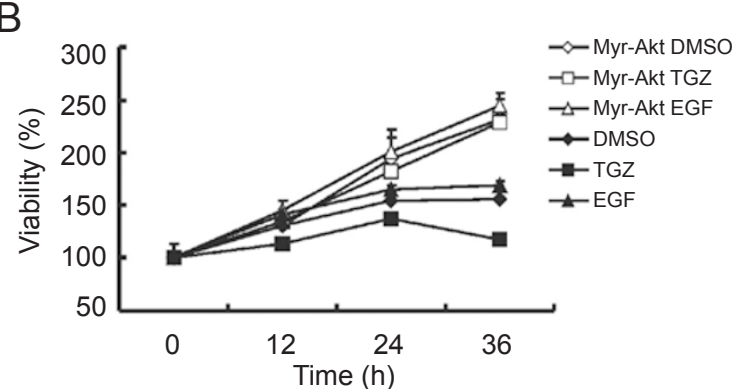

C $73 \mathrm{kDa}-\mathrm{a}-\mathrm{Myr}-\mathrm{Akt}$ $60 \mathrm{kDa}-\mathrm{T}-\mathrm{Akt}$ $42 \mathrm{kDa}-\infty-\beta$-actin

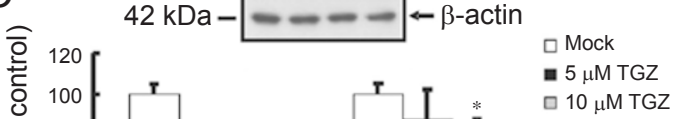

D

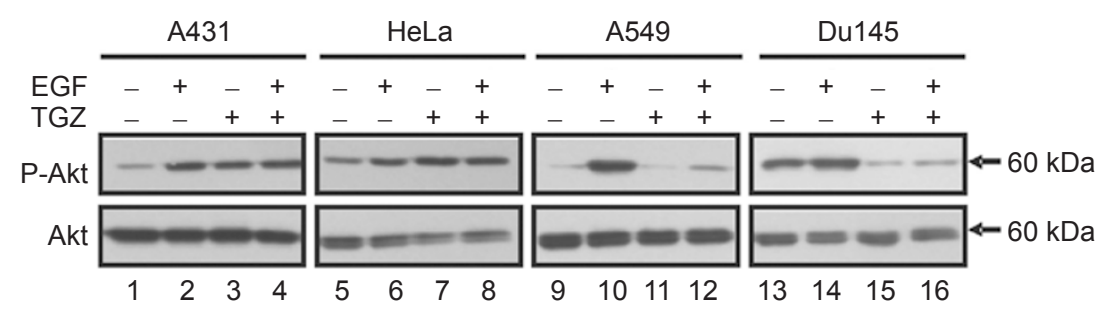

Figure 6 Inhibition of Akt phosphorylation contributes to TGZ-induced growth inhibition. (A) TGZ inhibits basal and EGF-induced phosphorylation of Akt. PAE, PAE-EGFR or PAE-EGFR-Y1068/1086F cells were grown to near confluence and serumstarved overnight. After pre-treatment of cells with DMSO or $50 \mu \mathrm{M} \mathrm{TGZ}$ for $30 \mathrm{~min}, 100 \mathrm{ng} / \mathrm{ml}$ EGF was added for an additional $10 \mathrm{~min}$. Akt phosphorylation was detected by immunoblotting with antibodies specific to phospho-Akt (P-Akt), while total Akt (T-Akt) was used as a loading control. (B) Constitutively active Akt abrogates TGZ-induced growth arrest. PAE-EGFR cells were transfected with plasmid pECFP-myr-Akt or pECFP vector and split into 96 -well plates $\left(0.5 \times 10^{4} /\right.$ well). 1 day post transfection, cells were treated with $10 \mu \mathrm{M} \mathrm{TGZ}$ or $10 \mathrm{ng} / \mathrm{ml}$ EGF for the times indicated and cell proliferation was assessed by the WST-1 method. Data represent the average (means \pm SD) of three independent experiments. (C) Constitutively active Akt abrogates TGZ-induced growth arrest. PAE-EGFR cells were transfected with pECFP-myr-Akt and pECFP vectors. 1 day later, the transfected cells were seeded on $60-\mathrm{mm}$ plates (300 cells/plate) containing 5 or $10 \mu \mathrm{M} \mathrm{TGZ.} 7$ days later, the colonies formed were counted. Data are averages (means $\pm \mathrm{SE}$ ) from two independent experiments. $* P<0.05 ; * * P<0.01$, compared with DMSO-treated cells. In parallel, expression of myr-Akt was measured at $48 \mathrm{~h}$ and 5 days post transfection. (D) TGZ inhibits phosphorylation of Akt in A549 and Du145 cells. A549, Du145, A431 or HeLa cells were serum-starved and incubated with DMSO or TGZ $(10 \mu \mathrm{M})$ for $30 \mathrm{~min}$ and $100 \mathrm{ng} / \mathrm{ml}$ EGF was then added for an additional 10 min. Akt phosphorylation was assessed by immunoblotting with antibodies specific to phospho-Akt (P-Akt), while total Akt (T-Akt) was used as a loading control. 
factors/receptor tyrosine kinases, and earlier studies have shown that TGZ acts on the PI3K-Akt pathway thus inhibiting endothelial cell proliferation and angiogenesis [35]. We found that Akt was constitutively activated in PAE-EGFR cells (Figure 6A, lane 5), and that TGZ could effectively block not only basal Akt phosphorylation (Figure 6A, compare lanes 5 and 7), but also more surprisingly, EGF-activated Akt hyperphosphorylation (Figure 6A, compare lanes 6 and 8). This inhibitory effect on Akt activation appears to be independent of the EGFRErk1/2 pathway, as TGZ inhibited Akt phosphorylation in PAE-EGFR-Y1068/1086F cells (Figure 6A, compare lanes 10 and 12). Intriguingly, this inhibitory effect on Akt activation also appears to be independent of PPAR $\gamma$, as TGZ inhibited Akt phosphorylation in LNCaP cells (Supplementary information, Figure S1B). Moreover, transient expression of the constitutively active Akt, myrAkt, in PAE-EGFR cells markedly overcame the growth arrest caused by TGZ (Figure 6B and 6C). In line with its inhibition of cancer cell proliferation, TGZ inhibited both basal and EGF-activated Akt phosphorylation in A549 and Du145 cells, but not in A431 and HeLa cells (Figure 6D). Therefore, it is likely that inhibition of Akt phosphorylation might account for the growth arrest in TGZ-responsive tumor cells. Why A431 and HeLa cells were resistant to TGZ's effects on growth arrest requires further investigation. Nevertheless, these results present an important pathway by which TGZ inhibits cell growth, simultaneously targeting EGFR to the endo-lysosomal degradation machinery and inhibiting Akt phosphorylation.

A variety of pharmacological and physiological stimulants can induce cleavage of EGF-like proteins, a group of structurally similar growth factors sharing the conserved six-cysteine motif (EGF-domain). EGF-like factors are synthesized as transmembrane precursors, which can undergo proteolytic cleavage at the cell surface by multiple matrix metalloproteases (MMPs) to release a mature soluble ectodomain. These soluble EGF-like factors can bind EGFR to trigger receptor dimerization and intracellular signal transduction cascades. Since TGZ may induce rapid production of EGF or EGF-like factors to activate EGFR signaling and EGFR internalization, it is critical to delineate whether this off-target effect of TGZ on EGFR is direct. An inhibitor of MMPs, GM6001 [36], was used to inhibit cleavage of pro-EGF ligands. Results showed that Erk1/2 activation was affected by the availability of EGF-like factors, while internalization and subsequent degradation of EGFR and Akt dephosphorylation were unaffected (Supplementary information, Figure S3). Therefore, transient activation of Erk1/2 by TGZ might in part be an indirect effect of secreted EGF or EGF-like factors that were induced by
TGZ. However, EGFR degradation and inhibition of Akt activation promoted by TGZ were independent of EGF or EGF-like factors.

\section{Discussion}

Several lines of evidence suggest that TZDs elicit PPAR $\gamma$-independent activation of the EGFR-Erk1/2signaling pathway. First, treatment of rat liver epithelial cells with Cig and TGZ induces EGFR-Erk1/2 activation absolutely independent of PPAR $\gamma$ [26], whereas inhibition of EGFR kinase activity or overexpression of the dominant negative Ras mutant blocks PPAR $\gamma$ agonistinduced Erk1/2 phosphorylation [25]. Second, EGFRdependent Erk1/2 activation induced by $15 \mathrm{~d}-\mathrm{PG}-\mathrm{J} 2$ can be blocked by EGFR kinase inhibitor or PP2, an Src family protein kinase inhibitor [37], but not by PPAR $\gamma$ antagonists [38]. Nevertheless, critical evidence of whether EGFR-Erk1/2 activation by TGZ contributes to the growth arrest of cancer cells and whether the SH2 and PTB domain proteins participate in PPAR $\gamma$ agonistactivated EGFR signaling is still lacking.

Previous studies have shown that PPAR $\gamma$ agonists can cause rapid MAPKs activation or Akt inhibition in multiple cell types [25, 39-41], yet their interrelationship has not been fully addressed. We have demonstrated that, like many other non-natural ligands that transactivate EGFR signaling [42], TGZ can cause rapid, EGFRdependent transient Erk1/2 activation, which has an absolute requirement for Grb2 binding to EGFR. Activation of MAPKs can increase phosphorylation of PPAR $\gamma \mathrm{s}$ and alter their transcription regulation, [43] eventually leading to inhibition of cell proliferation [44]. We found that TGZ only evoked rapid and transient phosphorlylation of Erk1/2, and more importantly, this transient Erk1/2 activation did not correlate with growth arrest in clonogenic assays. Therefore, we favor the model that Erk1/2 activation is not involved in the anti-neoplastic effects of TGZ. Rather, we propose that inhibition of Akt phosphorylation might be an important anti-neoplastic mechanism by which TGZ blocks aberrant EGFR signaling in cancer cells. This idea is further supported by our results showing that activation of Erk1/2 involved both EGF-like factors and TGZ. However, internalization and degradation of EGFR, as well as Akt dephosphorylation, could still occur in the presence of GM6001. Therefore, it seems that TGZ attenuates EGFR signaling by promoting EGFR degradation and reducing Akt phosphorylation, independent of the potential induction of EGF-like factors.

We have also shown that TGZ may target EGFR directly for receptor internalization, even though TGZ's 
affinity for EGFR seems to be lower than EGF. Further rigorous biochemical analysis is necessary to address this issue. Nevertheless, it is clear that TGZ differs from the genomic EGFR ligand in several ways. Firstly, in contrast to EGF (at concentrations of $20 \mathrm{ng} / \mathrm{ml}$ or higher), activation of the EGFR-Erk1/2-signaling pathway by TGZ (at high concentrations that have no apparent cytotoxicity to PAE cells) requires phosphorylation of EGFR Y1068/1086. Secondly, EGF at low concentrations promoted cell proliferation primarily through the activation of EGFR kinase and downstream signaling pathways (for example, Erk1/2, Akt), while EGF at high concentrations induced cell cycle or growth arrest (Supplementary information, Figure S4), in agreement with previous reports [45, 46]. In contrast, TGZ attenuated overactive EGFR signaling by inhibition of Akt phosphorylation and induction of effective endo-lysosomal degradation of the receptor, leading to growth arrest in aberrant EGFR-overexpressing cells. Although it has been suggested that TGZ has liver toxicity, we speculate that EGFR degradation by TGZ would be a good complement to the current cancer therapeutic regime of EGFR kinase inhibition, just as R-etodolac combined with a HER kinase inhibitor has an additive effect on inhibiting tumor progression [44].

Grb2 is a crucial adaptor in the regulation of both EGFR signaling and its endosomal trafficking. Besides its well-characterized role in mediating positive signaling in the EGFR-Erk1/2 pathway, Grb2 can also downregulate EGFR signaling by accelerating c-Cbl-dependent sorting of activated EGFR for degradation [32]. In our study, TGZ-induced degradation of EGFR and growth inhibition was partially abolished if Grb2-binding sites were mutated (PAE-EGFR-Y1068/86F). Recently, Grb2 has been implicated in the oncogenesis of many human cancers and has been a target for anti-cancer drug development $[47,48]$. Given that TGZ inhibits cancerous cell proliferation partly by promoting EGFR degradation, the balance between attenuation of EGFR signaling and targeting of Grb2 should be considered to maximize downregulation of aberrant EGFR activation in cancer cells.

\section{Materials and Methods}

\section{Reagents}

Antibodies specific to phospho-Erk1/2, phosphor-Akt, total Erk1/2 and total Akt were from Cell Signaling Technology (Beverly, MA, USA). Anti-EGFR monoclonal antibodies were purchased from Chemicon (Temecula, CA, USA). PD98059, TGZ, anti- $\beta$-actin antibodies and all analytical-grade chemicals were from Sigma (St Louis, MO, USA). Cig, pioglitazone rosiglitazone and GW9662 were from Cayman Chemical Co. (Ann Arbor, MI, USA). Rh-EGF and Texas Red conjugated Transferrin were from Molecular Probes (Eugene, OR, USA). Effectene transfection kits were from Qiagen (Hilden, Germany). A dual Luciferase reporter assay system was purchased from Promega (Madison, WI, USA). Cell Proliferation Reagent WST-1 was from Roche Diagnostics (Mannheim, Germany). Streptavidin Sepharose High Performance beads were from GE Healthcare.

\section{Plasmids}

Various fluorescent fusion protein constructs expressing EGFRGFP and its mutant derivatives as indicated, and Grb2-CFP are described elsewhere [38, 49]. The DsRed-Shc expression plasmid was constructed by PCR-amplifying full-length $\mathrm{H}-\mathrm{Shc}$ and ligating it into pDsRed2-N1 (Clontech, CA, USA) between the EcoRI and $K p n I$ restriction sites. pCMV-flag-PPAR $\gamma$ was constructed by PCR-amplifying full-length human PPAR $\gamma$ coding sequence into a pCMV-flag vector between the XhoI and NotI sites. PPAR $\gamma$ reporter plasmid PPRE3-tk-Luc was kindly provided by Dr Y Shang (Beijing University, Health Science Center). Plasmids expressing the wild-type (pcDNA3-hPPAR $\gamma$ ) and AF2 domain double mutant (pcDNA3-hPPAR $\gamma \mathrm{DN}$ ) PPAR $\gamma$ were kindly provided by $\mathrm{Dr} \mathrm{X}$ Shen (Institute of Biophysics, CAS).

\section{Cells and reporter assays}

Porcine aorta endothelial stable cell lines, which expressed similar amounts (1-4 $\times 10^{5}$ receptors/cell) of wild-type EGFR (PAE-EGFR) or mutant EGF receptors (PAE-C'1022, PAE-EGFRY1068/1086F, PAE-EGFR-Y1148/1173F), were selected using G418. As indicated, a PAE stable cell line expressing GFP fusion EGFR was established in a similar way. Cells were maintained in the following media supplemented with $10 \%$ FBS and $1 \%$ penicillin/ streptomycin: PAE and derivative cells were maintained in F12 medium (HyClone); 293T, A431 and HeLa cells in DMEM (HyClone) and A549, DU145 and LNCaP cells in RPMI 1640 medium (HyClone). Transient transfection of PAE cells was performed with Effectene according to the manufacturer's instructions (Qiagen). In brief, cells (about $1 \times 10^{5}$ ) were transfected in triplicate with $0.2 \mu \mathrm{g}$ PPRE reporter plasmid (PPRE3-tk-luc) and $3 \mathrm{ng}$ phRL-CMV (Promega) as an internal control for transfection efficiency. Cells were stimulated with TGZ $(25$ or $50 \mu \mathrm{M})$ or recombinant human EGF (100 ng/ml) $24 \mathrm{~h}$ post transfection. Dual luciferase assays (Promega) were performed in a TD-20 luminometer (Turner Designs). Data presented are the average (means \pm SD) of triplicate measurements of firefly luciferase activity after normalization with Renilla luciferase activity.

\section{Western blotting}

Whole cell lysates were prepared using Triton-X 100/glycerol buffer, as described previously [30, 31]. Proteins were separated using SDS-PAGE and transferred to nitrocellulose membranes (Pall, Pensacola, FL, USA). Western blotting was performed with antibodies as indicated using an enhanced chemiluminescence system (SuperSignal ECL, Pierce).

\section{Quantitative real-time $P C R$}

Total RNA extraction and real-time PCR conducted in an iCycler (BioRad) were performed using previously described methods [50]. Quantitative analysis was performed using the threshold procedure after normalizing to the expression of $18 \mathrm{~S}$ RNA. The primers used were as follows: EGFR forward: 5'-TGT CGA TGG ACT TCC AGA AC-3' and reverse: 5'-ATT GGG ACA GCT TGG ATC A-3'; 
Sus scrofa $18 \mathrm{~S}$ ribosomal RNA primers, forward: 5'-TTG GAT GTG GTA GCC GTT TC-3' and reverse: 5'-GAT GGT AGT CGC CGT GCC-3'.

\section{Internalization of EGFR}

Fluorescence microscopy PAE cells expressing EGFR-GFP or transiently co-transfected with CFP-Grb2 and DsRed2-Shc were grown on coverslips and incubated with $50 \mu \mathrm{M} \mathrm{TGZ}$ at $37{ }^{\circ} \mathrm{C}$ for $30 \mathrm{~min}$. Cells were fixed and images were acquired using previously described methods [51]. About 10 fluorescence-positive cells were analyzed per field of view and at least 5 different fields were analyzed.

Flow cytometry (1) Panning assays: PAE-EGFR cells were starved in F12 medium containing $0.1 \%$ FBS overnight, followed by chilling on ice in F12 without FBS for $20 \mathrm{~min}$. TGZ or other TZDs, at different doses were added for $0.5,1$ or $2 \mathrm{~h}$. Unstained EGF was also added (100 ng/ml, $1 \mathrm{~h}$ ) as a positive control. RhEGF $(2 \mathrm{ng} / \mathrm{ml})$ was then added for $1 \mathrm{~h}$ before cells were washed with ice-cold PBS and resuspended in F12 complete medium. All steps were performed at $4{ }^{\circ} \mathrm{C}$. Fluorescence intensities of Rh-EGF on the cell surface were assessed by flow cytometry (FACSVantage SE, $568 \mathrm{~nm}$ excitation) using CellQuest Pro software (BD Biosciences, San Jose, CA, USA). Relative inhibition efficiencies were plotted as the ratio of TZD or unstained EGF-reduced Rhodamine fluorescence intensity to the fluorescence intensity from Rh-EGF incubation alone. Results presented are the average of three independent experiments. (2) Internalization competition assays: starved PAE cells $(80 \%$ confluence) were pre-treated with TGZ $(25$ or $50 \mu \mathrm{M})$ at $37^{\circ} \mathrm{C}$ for $30 \mathrm{~min}$. Unstained EGF was also added (100 ng/ml, $6 \mathrm{~min}$ ) as a positive control. Rh-EGF (2 ng/ $\mathrm{ml}$ ) was then added. After incubating for $6 \mathrm{~min}$ at $37^{\circ} \mathrm{C}$, excessive Rh-EGF was rinsed off by an acid wash $(0.2 \mathrm{M}$ acetic acid, $\mathrm{pH} 2.8,0.5 \mathrm{M} \mathrm{NaCl})$ at room temperature. Cells were dislodged with trypsin and resuspended in F12 complete medium $\left(1.5 \times 10^{6}\right.$ cells $/ \mathrm{ml}$ ). The internalization of Rh-EGF was analyzed with flow cytometry. Relative inhibition efficiency was plotted as the ratio of TGZ or unstained EGF-reduced Rhodamine fluorescence intensity to fluorescence intensity from Rh-EGF incubation alone. Results presented are the average of two independent experiments.

\section{Clonogenic assays}

PAE, PAE-EGFR, PAE-EGFR-Y1068/1086F cells or cancer cells as indicated, were seeded in complete medium containing 5, 10 or $20 \mu \mathrm{M}$ TGZ (DMSO solvent was used as a control). Plates ( 300 cells/plate) were incubated at $37^{\circ} \mathrm{C}$ for 1 week before cell colonies were counted by Giemsa dye staining. Relative cell growth rates (the percentage of colonies in the TGZ treatment divided by those in the DMSO control treatment) were plotted from the average of three independent experiments. Statistical analysis was performed using Student's $t$-tests.

\section{Cell proliferation assays}

Cells were seeded $\left(0.5 \times 10^{4}\right.$ cells/well $)$ in a 96 -well plate in triplicates and incubated for $12 \mathrm{~h}$ before TGZ was added. After the indicated times, cell proliferation rates were measured using the WST-1 method (Roche) in a plate reader (450 nm, Opsys MR, Dynex Tech) according to the manufacturer's instructions. Data presented are the average (means \pm SD) from three independent experiments.

\section{Acknowledgments}

We thank Dr Yongfeng Shang (Beijing University, Health Science Center) for the PPAR $\gamma$ reporter plasmid and Dr Youyong Lu (Beijing University, School of Oncology) for Du145 cells. We especially thank Mr Chunchun Liu of Institute of Biophysics, Chinese Academy of Sciences for expert technical assistance. This work was supported in part by grants to Hong Tang from the National Basic Research Program of the Ministry of Science and Technology, China (2007DFC30190) and Chinese Academy of Sciences (kscx-1-YW-10).

\section{References}

1 Mangelsdorf DJ, Thummel C, Beato M, et al. The nuclear receptor superfamily: the second decade. Cell 1995; 83:835-839.

2 Evans RM, Barish GD, Wang YX. PPARs and the complex journey to obesity. Nat Med 2004; 10:355-361.

3 Kliewer SA, Forman BM, Blumberg B, et al. Differential expression and activation of a family of murine peroxisome proliferator-activated receptors. Proc Natl Acad Sci USA 1994; 91:7355-7359.

4 Issemann I, Green S. Activation of a member of the steroid hormone receptor superfamily by peroxisome proliferators. Nature 1990; 347:645-650.

5 Dreyer C, Krey G, Keller H, et al. Control of the peroxisomal beta-oxidation pathway by a novel family of nuclear hormone receptors. Cell 1992; 68:879-887.

6 Berger J, Moller DE. The mechanisms of action of PPARs. Annu Rev Med 2002; 53:409-435.

7 Tontonoz P, Hu E, Spiegelman BM. Stimulation of adipogenesis in fibroblasts by PPAR gamma 2, a lipid-activated transcription factor. Cell 1994; 79:1147-1156.

8 Tontonoz P, Singer S, Forman BM, et al. Terminal differentiation of human liposarcoma cells induced by ligands for peroxisome proliferator-activated receptor gamma and the retinoid X receptor. Proc Natl Acad Sci USA 1997; 94:237-241.

9 Demetri GD, Fletcher CD, Mueller E, et al. Induction of solid tumor differentiation by the peroxisome proliferator-activated receptor-gamma ligand troglitazone in patients with liposarcoma. Proc Natl Acad Sci USA 1999; 96:3951-3956.

10 Elstner E, Muller C, Koshizuka K, et al. Ligands for peroxisome proliferator-activated receptorgamma and retinoic acid receptor inhibit growth and induce apoptosis of human breast cancer cells in vitro and in BNX mice. Proc Natl Acad Sci USA 1998; 95:8806-8811.

11 Koeffler HP. Peroxisome proliferator-activated receptor gamma and cancers. Clin Cancer Res 2003; 9:1-9.

12 Kubota T, Koshizuka K, Williamson EA, et al. Ligand for peroxisome proliferator-activated receptor gamma (troglitazone) has potent antitumor effect against human prostate cancer both in vitro and in vivo. Cancer Res 1998; 58:3344-3352.

13 Sarraf P, Mueller E, Jones D, et al. Differentiation and reversal of malignant changes in colon cancer through PPARgamma. Nat Med 1998; 4:1046-1052.

14 Yin F, Bruemmer D, Blaschke F, et al. Signaling pathways 
involved in induction of GADD45 gene expression and apoptosis by troglitazone in human MCF-7 breast carcinoma cells. Oncogene 2004; 23:4614-4623.

15 Baek SJ, Wilson LC, Hsi LC, Eling TE. Troglitazone, a peroxisome proliferator-activated receptor gamma (PPAR gamma) ligand, selectively induces the early growth response-1 gene independently of PPAR gamma. A novel mechanism for its antitumorigenic activity. $J$ Biol Chem 2003; 278:5845-5853.

16 Akasaki Y, Liu G, Matundan HH, et al. A peroxisome proliferator-activated receptor-gamma agonist, troglitazone, facilitates caspase- 8 and -9 activities by increasing the enzymatic activity of protein-tyrosine phosphatase-1B on human glioma cells. J Biol Chem 2006; 281:6165-6174.

17 Feinstein DL, Spagnolo A, Akar C, et al. Receptor-independent actions of PPAR thiazolidinedione agonists: is mitochondrial function the key? Biochem Pharmacol 2005; 70:177-188.

18 Shiau CW, Yang CC, Kulp SK, et al. Thiazolidenediones mediate apoptosis in prostate cancer cells in part through inhibition of Bcl-xL/Bcl-2 functions independently of PPARgamma. Cancer Res 2005; 65:1561-1569.

19 Palakurthi SS, Aktas H, Grubissich LM, Mortensen RM, Halperin JA. Anticancer effects of thiazolidinediones are independent of peroxisome proliferator-activated receptor gamma and mediated by inhibition of translation initiation. Cancer Res 2001; 61:6213-6218.

20 Hynes NE, Lane HA. ERBB receptors and cancer: the complexity of targeted inhibitors. Nat Rev Cancer 2005; 5:341-354.

21 Yarden Y, Sliwkowski MX. Untangling the ErbB signalling network. Nat Rev Mol Cell Biol 2001; 2:127-137.

22 Le Roy C, Wrana JL. Clathrin- and non-clathrin-mediated endocytic regulation of cell signalling. Nat Rev Mol Cell Biol 2005; 6:112-126.

23 Sorkin A, Von Zastrow M. Signal transduction and endocytosis: close encounters of many kinds. Nat Rev Mol Cell Biol 2002; 3:600-614.

24 Moscatello DK, Holgado-Madruga M, Godwin AK, et al. Frequent expression of a mutant epidermal growth factor receptor in multiple human tumors. Cancer Res 1995; 55:5536-5539.

25 Gardner OS, Dewar BJ, Earp HS, Samet JM, Graves LM. Dependence of peroxisome proliferator-activated receptor ligand-induced mitogen-activated protein kinase signaling on epidermal growth factor receptor transactivation. $J$ Biol Chem 2003; 278:46261-46269.

26 Gardner OS, Shiau CW, Chen CS, Graves LM. Peroxisome proliferator-activated receptor gamma-independent activation of p38 MAPK by thiazolidinediones involves calcium/ calmodulin-dependent protein kinase II and protein kinase R. correlation with endoplasmic reticulum stress. J Biol Chem 2005; 280:10109-10118.

27 Calnek DS, Mazzella L, Roser S, Roman J, Hart CM. Peroxisome proliferator-activated receptor gamma ligands increase release of nitric oxide from endothelial cells. Arterioscler Thromb Vasc Biol 2003; 23:52-57.

28 Li M, Lee TW, Yim AP, Mok TS, Chen GG. Apoptosis induced by troglitazone is both peroxisome proliferator-activated receptor-gamma- and ERK-dependent in human non-small lung cancer cells. J Cell Physiol 2006; 209:428-438.

29 Willson TM, Brown PJ, Sternbach DD, Henke BR. The PPARs: from orphan receptors to drug discovery. $\mathrm{J} \mathrm{Med} \mathrm{Chem}$
2000; 43:527-550.

30 Khan EM, Heidinger JM, Levy M, et al. Epidermal growth factor receptor exposed to oxidative stress undergoes Src- and caveolin-1-dependent perinuclear trafficking. J Biol Chem 2006; 281:14486-14493.

31 Sigismund S, Woelk T, Puri C, et al. Clathrin-independent endocytosis of ubiquitinated cargos. Proc Natl Acad Sci USA 2005; 102:2760-2765.

32 Waterman H, Yarden Y. Molecular mechanisms underlying endocytosis and sorting of ErbB receptor tyrosine kinases. FEBS Lett 2001; 490:142-152.

33 Chaffer CL, Thomas DM, Thompson EW, Williams ED. PPARgamma-independent induction of growth arrest and apoptosis in prostate and bladder carcinoma. BMC Cancer 2006; 6:53.

34 Keshamouni VG, Reddy RC, Arenberg DA, et al. Peroxisome proliferator-activated receptor-gamma activation inhibits tumor progression in non-small-cell lung cancer. Oncogene 2004; 23:100-108.

35 Goetze S, Eilers F, Bungenstock A, et al. PPAR activators inhibit endothelial cell migration by targeting Akt. Biochem Biophys Res Commun 2002; 293:1431-1437.

36 Tatin F, Varon C, Genot E, Moreau V. A signalling cascade involving $\mathrm{PKC}, \mathrm{Src}$ and $\mathrm{Cdc} 42$ regulates podosome assembly in cultured endothelial cells in response to phorbol ester. $J$ Cell Sci 2006; 119:769-781.

37 Ichiki T, Tokunou T, Fukuyama K, et al. 15-Deoxy-Delta12, 14-prostaglandin $\mathrm{J} 2$ and thiazolidinediones transactivate epidermal growth factor and platelet-derived growth factor receptors in vascular smooth muscle cells. Biochem Biophys Res Commun 2004; 323:402-408.

38 Sorkina T, Huang F, Beguinot L, Sorkin A. Effect of tyrosine kinase inhibitors on clathrin-coated pit recruitment and internalization of epidermal growth factor receptor. $J$ Biol Chem 2002; 277:27433-27441.

39 Lennon AM, Ramauge M, Dessouroux A, Pierre M. MAP kinase cascades are activated in astrocytes and preadipocytes by 15-deoxy-Delta(12-14)-prostaglandin J(2) and the thiazolidinedione ciglitazone through peroxisome proliferator activator receptor gamma-independent mechanisms involving reactive oxygenated species. J Biol Chem 2002; 277:29681-29685.

40 Mounho BJ, Thrall BD. The extracellular signal-regulated kinase pathway contributes to mitogenic and antiapoptotic effects of peroxisome proliferators in vitro. Toxicol Appl Pharmacol 1999; 159:125-133.

41 Rokos CL, Ledwith BJ. Peroxisome proliferators activate extracellular signal-regulated kinases in immortalized mouse liver cells. J Biol Chem 1997; 272:13452-13457.

42 Fischer OM, Hart S, Gschwind A, Ullrich A. EGFR signal transactivation in cancer cells. Biochem Soc Trans 2003; 31:1203-1208.

$43 \mathrm{Hu}$ E, Kim JB, Sarraf P, Spiegelman BM. Inhibition of adipogenesis through MAP kinase-mediated phosphorylation of PPARgamma. Science 1996; 274:2100-2103.

44 Hedvat M, Jain A, Carson DA, et al. Inhibition of HERkinase activation prevents ERK-mediated degradation of PPARgamma. Cancer Cell 2004; 5:565-574.

45 Zhao X, Dai W, Zhu H, et al. Epidermal growth factor (EGF) induces apoptosis in a transfected cell line expressing EGF 
receptor on its membrane. Cell Biol Int 2006; 30:653-658.

46 Kamer AR, Sacks PG, Vladutiu A, Liebow C. EGF mediates multiple signals: dependence on the conditions. Int J Mol Med 2004; 13:143-147.

47 Tari AM, Hung MC, Li K, Lopez-Berestein G. Growth inhibition of breast cancer cells by Grb2 downregulation is correlated with inactivation of mitogen-activated protein kinase in EGFR, but not in ErbB2, cells. Oncogene 1999; 18:1325-1332.

48 Dankort D, Maslikowski B, Warner N, et al. Grb2 and Shc adaptor proteins play distinct roles in Neu (ErbB-2)-induced mammary tumorigenesis: implications for human breast can- cer. Mol Cell Biol 2001; 21:1540-1551.

49 Jiang X, Sorkin A. Coordinated traffic of Grb2 and Ras during epidermal growth factor receptor endocytosis visualized in living cells. Mol Biol Cell 2002; 13:1522-1535.

50 Chen Y, Chen J, Xiong Y, et al. Internalization of CD40 regulates its signal transduction in vascular endothelial cells. Biochem Biophys Res Commun 2006; 345:106-117.

51 Chen J, Chen L, Wang G, Tang H. Cholesterol-dependent and -independent CD40 internalization and signaling activation in cardiovascular endothelial cells. Arterioscler Thromb Vasc Biol 2007; 27:2005-2013.

(Supplementary information is linked to the online version of the paper on the Cell Research website.) 